Agriculture, Agrobusiness and Biotechnology

\title{
Enzyme Detection and Metabolic Process Tracking of Ethanol Fermentation by a Natural Alginate Fermentation Strain
}

\author{
Wen Zhang1*, Xiaohui Ren', Liyin Bao². \\ ${ }^{1}$ Yanshan University - College of Environment and Chemistry Engineering, Qinhuangdao, China; ${ }^{2}$ Institute of \\ Forensic Science of Ministry of Public Security P. R. C., Beijing, China.
}

\begin{abstract}
Alginate is a major component of brown algae, but it cannot be utilized for ethanol fermentation by industrial microorganisms. A natural alginate degrading and ethanol producing strain was obtained in our previous research. However, the research on the ethanol metabolism process of the natural alginate fermentation strain is lacked. In this research, the key enzyme and metabolic process of ethanol fermentation were studied. Three kinds of key enzyme including alginate lyase, pyruvate dehydrogenase and ethanol dehydrogenase were determined. The enzyme activity in the metabolic process was relatively high at 60-96 $h$ which was the most important period during the fermentation. Meanwhile the concentration change of the important substances including soluble sugar, reducing sugar, acidity, pyruvic acid and ethanol were tracked and analyzed. Total soluble sugar and reducing sugar change tendency during the fermentation was similar. In the whole fermentation process, the fermentation broth was acidic. The value of pyruvic acid content reached highest at $72 \mathrm{~h}$. During 48-96 $h$, the growth of ethanol concentration was very obvious. The alginate metabolic process in natural alginate fermentation strain was to generate extracellular alginate lyase to degrade alginate to produce reducing sugar, and then some intermediate metabolites formed such as pyruvic acid. Finally under the effect of pyruvate dehydrogenase and ethanol dehydrogenase, ethanol was produced.
\end{abstract}

Keywords: Alginate fermentation strain; Brown algae; Ethanol metabolism process

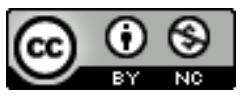

*Author for correspondence: gillianjay@126.com 


\section{INTRODUCTION}

Bio-ethanol is a promising bio-fuel candidate to substitute or replace liquid fossil fuels such as gasoline ${ }^{1}$. Bio-ethanol production from varying biomass sources has become an area of intense research due to the social and environmental implication of global warming, the shortage of fossil fuels, and increased cost of oil ${ }^{2,3}$. Scientists are searching for different methods for efficient bio-ethanol production from different biomass sources, such as corn ${ }^{4}$, wood ${ }^{5}$, sugarcane ${ }^{6}$, and corn straw ${ }^{7}$.

But most commercial bio-ethanol production (79.3\%) is obtained from staple food resources $^{8}$. The higher amounts of food materials turned to bio-fuel production could have devastating effects on food supply around the world and this may threaten food security. Because of these limitations, a second generation of bio-ethanol production based on lignocellulose biomass from agricultural and forest residues and dedicated energy crop feedstock has been developed ${ }^{9}$. However, the current technologies for lignocellulose ethanol fermentation have to overcome the cost of the complex processes needed to release simple sugars from recalcitrant polysaccharides ${ }^{10}$. With limited land area, pretreatment technical difficulties and low conversion rate, much more needs to be done in bio-ethanol production from lignocellulose. And the increasing need for energy consumption is expected to continue as the world's population is expected to increase. In order to meet the expected increasing demand for bio-ethanol, it is necessary to find alternative biomass sources, particularly those that do not rely on using large amounts of agricultural land ${ }^{11,12}$.

Marine seaweed is a multicellular photosynthetic organism and a potential biomass resource for the full or partial substitution and displacement of terrestrial biomass to produce sustainable biofuels and biochemical products ${ }^{13,14}$. Marine seaweeds do not require arable land, fertilizer, or fresh water. They are of high photosynthetic efficiency and production rate, and free of land management and adverse impacts on food supplies ${ }^{15}$. Also they contain a low concentration of lignin and sugars which can be easily released by simple operations such as milling or crushing, so seaweeds are proposed as one of the most promising biomass materials for ethanol production ${ }^{1,16,17}$.

Marine seaweeds are classified into three groups: brown algae, green algae, and red algae. Brown algae, as the second most abundant marine biomass, have several key features of an ideal feedstock for bio-fuel production. Brown algae contain about 30 $67 \%$ carbohydrate by dry weight, and the main components of polysaccharides are alginate, laminaran, and mannitol ${ }^{18}$. Laminaran and mannitol can be easily used by microbes and converted into bio-ethanol, but industrial microbes cannot degrade alginate as a carbon source ${ }^{19,20}$. The potential of brown algae to produce bio-ethanol cannot be fully exhibited. To utilize alginate, a series of lyases such as alginate lyase and ethanol dehydrogenase, are needed. Gene engineering might be a good way of improving the conversion rate of alginate. Takeda et al. ${ }^{19}$ developed an integrated bacterial system for converting alginate to ethanol using a metabolically modified, alginate-assimilating, pit-forming bacterium, Sphingomonas sp. A1, which accumulated $13.0 \mathrm{~g} \mathrm{~L}^{-1}$ ethanol in $3 \mathrm{~d}$ using alginate as the sole carbon source. But there were still drawbacks in the genetically modified strain, because ethanol from this strain was produced under aerobic conditions, and the oxygen supply should be strictly controlled to maintain a balance between energy and ethanol production, since an oversupply of oxygen would lead to low ethanol production.

In order to improve the utilization rate of algae, high alginate fermentation strains should be obtained not only from gene engineering technology but also from natural isolation. In our previous research ${ }^{21}$, alginate degrading strains were isolated from different samples with alginate as the only carbon source and several strains that showed ethanol fermentation ability were obtained through TTC selection 
Enzyme and metabolic process tracking

experiments and fermentation experiments. The ethanol yield of strain 5 was the highest, which was $0.154 \mathrm{~g} \mathrm{~g}^{-1}$ (ethanol to alginate). The identification of strain 5 was carried out through 26S rDNA sequence by Beijing Sunbiotech Co. Ltd., which showed that strain 5 was $99 \%$ identical to Meyerozyma guilliermondii. The fermentation experiments of $L$. japonica by strain 5 showed that Meyerozyma guilliermondii might be a promising strain for ethanol production from algae. However, the research on the ethanol metabolism process of the natural alginate fermentation strain is lacked. And the key enzymes and important intermediate products are still not clear. Whether the ethanol metabolism process of the natural alginate fermentation strain is the same as the genetically engineered bacteria is not known. The seaweed as raw materials for bio- ethanol production is becoming the focus of attention in the world in the field of energy. In order to reach the maximum ethanol production, the research on alginate fermentation and alginate metabolism process is very important. The research on alginate metabolic pathway, metabolites and important enzymes will provide theoretical basis for further metabolic and progress control, and also for gene modification and industrial application.

\section{MATERIALS AND METHODS}

\section{Materials}

All chemicals of analytical reagent grade were purchased from Beijing Chemical Factory (Beijing, China). All the biochemical reagents were bought from Beijing Biological Technology Factory (Beijing, China). The strains were stored in the tube culture at $4{ }^{\circ} \mathrm{C}$ and also were stored in glycerol solution ${ }^{22}$. General biological equipments are purchased from Shanghai Precision Instrument Co., LTD (Shanghai, China).

\section{Culture Media and Microorganism Culture}

Yeast Extract Peptone Dextrose Medium (YPD medium) was used as the enrichment medium containing $10 \mathrm{~g} / \mathrm{L}$ yeast extract, $20 \mathrm{~g} / \mathrm{L}$ peptone and $20 \mathrm{~g} / \mathrm{L}$ glucose. And the $\mathrm{pH}$ of YPD medium was adjusted to 4-5. The agar (2\%) was added to the YPD medium to make YPD solid culture medium. The composition of fermentation culture medium was: $10.8 \mathrm{~g} / \mathrm{L}\left(\mathrm{NH}_{4}\right)_{2} \mathrm{SO}_{4}, 5.0 \mathrm{~g} / \mathrm{L} \mathrm{KH}_{2} \mathrm{PO}_{4}, 1.1 \mathrm{~g} / \mathrm{L} \mathrm{MgSO}_{4} \cdot 7 \mathrm{H}_{2} \mathrm{O}$, and $20 \mathrm{~g} / \mathrm{L}$ alginate. And the glycerol method was used for the preservation of the yeast with the glycerol concentration of $15 \%$.

\section{Ethanol production experiments from alginate}

Ethanol production experiments were carried out with alginate as the only carbon source. The glycerol frozen stored strain was firstly put in $37^{\circ} \mathrm{C}$ water bath for rapid thawing, and then plate streaking recovery was done. The survival condition and relevant biochemical parameter of strain was detected and also the colonial morphology was observed. If the biological characteristics did not change, the strain was used for the further experiments. Strains with high activity were first activated in YPD broth for $24 \mathrm{~h}$ in a shaking incubator at $150 \mathrm{r} / \mathrm{min}$ and $30^{\circ} \mathrm{C}$. And then it was inoculated to the fermentation medium with inoculation amount of $5 \%$. All the fermentation experiments were carried out in $150 \mathrm{~mL}$ flasks with $50 \mathrm{~mL}$ working medium, with an initial $\mathrm{pH}$ of 5.0. The flasks were autoclaved at $121^{\circ} \mathrm{C}$ for $15 \mathrm{~min}$, inoculated with various strains after cooling to room temperature, and then they were capped with butyl rubber covers to create an anaerobic condition. All the flasks were cultured in a shaking incubator, with culture conditions as follows: $150 \mathrm{r} / \mathrm{min}$ and 30 ${ }^{\circ} \mathrm{C}$ for different fermentation time. 


\section{The key enzyme research}

Alginate is a major polysaccharide in brown algae. In order to convert alginate to bio-ethanol, alginate fermentation strains should degrade alginate to produce some intermediate products and finally generate ethanol. In this research, three kinds of important enzyme were selected to detect and measured.

Alginate lyase was obtained and the enzyme activity was measured according to the reference ${ }^{23}$. After cultured for some days in the shaking incubator $\left(30{ }^{\circ} \mathrm{C}, 150\right.$ $\mathrm{r} / \mathrm{min}$ ), the fermentation liquor was centrifuged at $5000 \mathrm{r} / \mathrm{min}$ for $10 \mathrm{~min}$, and the supernatant was crude alginate lyase. $0.1 \mathrm{~mL}, 0.2 \mathrm{~mL}, 0.3 \mathrm{~mL}, 0.4 \mathrm{~mL}, 0.5 \mathrm{~mL}$ crude alginate lyase was added to $0.9 \mathrm{~mL}, 0.8 \mathrm{~mL}, 0.7 \mathrm{~mL} 、 0.6 \mathrm{~mL} 、 0.5 \mathrm{~mL}$ alginate substrate (dissolved in $0.05 \mathrm{~mol} / \mathrm{L}$ potassium-phosphate buffer) respectively, mixed and kept in $40{ }^{\circ} \mathrm{C}$ water for $10 \mathrm{~min}$. The reducing sugar produced was measured by DNS method, with alginate lyase replaced by ionized water in the control group.

Pyruvate dehydrogenase was obtained and the enzyme activity was measured according to a refined method based on the reference ${ }^{24}$. The fermentation liquor was centrifuged at $3500 \mathrm{r} / \mathrm{min}$ for $20 \mathrm{~min}$, and then was washed by $10 \mathrm{mmol} / \mathrm{L}$ sodium phosphate buffer which contained 2 mmol EDTA to form precipitation. The solution was centrifuged at $3500 \mathrm{r} / \mathrm{min}$ for $20 \mathrm{~min}$, and the precipitate was dissolved by sodium phosphate $(100 \mathrm{mmol} / \mathrm{L})$ and $\mathrm{MgCl}_{2}$ buffer $(2 \mathrm{mmol} / \mathrm{L})$. Then the solution was treated by ultrasonic crushing with the whole treating time of $10 \mathrm{~min}$, ultrasonic time of $1 \mathrm{~s}$ and the time interval of $1 \mathrm{~s}$. The solution was centrifuged at $3500 \mathrm{r} / \mathrm{min}$ for $20 \mathrm{~min}$ and the supernatant was crude pyruvate dehydrogenase. Enzyme activity was measured according to the reference.

Alcohol dehydrogenase was obtained and the enzyme activity was measured according to a refined method based on the reference ${ }^{25}$. After cultured for some days in the shaking incubator $\left(30{ }^{\circ} \mathrm{C}, 150 \mathrm{r} / \mathrm{min}\right), 40 \mathrm{~mL}$ fermentation liquor was centrifuged at $5000 \mathrm{r} / \mathrm{min}$ for $5 \mathrm{~min}$, and the cells were washed and suspended in 20 $\mathrm{mL}$ potassium-phosphate buffer $(0.05 \mathrm{~mol} / \mathrm{L}, \mathrm{pH} 8.0)$. Added with $200 \mu \mathrm{L} 32 \mathrm{mg} / \mathrm{mL}$ lysozyme, the solution was kept at $37^{\circ} \mathrm{C}$ for $30 \mathrm{~min}$. Then the beaker containing the solution was put in the iced water and cells were disrupted by ultrasonic cell disintegrator, the procedure was: ultrasonic disruption for $1 \mathrm{~s}$, pause $3 \mathrm{~s}$, and the whole time of the procedure was $15 \mathrm{~min}$ at the power of $320 \mathrm{~W}$. Then the solution was centrifuged at $10000 \mathrm{r} / \mathrm{min}$ for $15 \mathrm{~min}$. The supernatant was kept and stored at 4 ${ }^{\circ} \mathrm{C}$. Enzyme activity was measured according to the reference.

\section{The concentration measurement of pyruvic acid}

The concentration of pyruvic acid in the fermentation liquid was measured by the efficient liquid chromatography spectrometry. It is a kind of chromatography, through high pressure infusion system, using liquid as mobile phase, the mixed solvent, buffer mobile phase pumping with a stationary phase of chromatographic column. The pattern enters the two phases for separation and then into the detector to get the result.

The determination condition was as follows: chromatographic column of C18 column, column temperature of $30^{\circ} \mathrm{C}$, mobile phase of acetonitrile and potassium dihydrogen phosphate, $\mathrm{pH}$ of 3.0 , the flow rate of $8 \mathrm{~mL} / \mathrm{min}$, and wavelength of 210 $\mathrm{nm}$. The preparation method of the mobile phase was as follows. $2.72 \mathrm{~g} \mathrm{KH}_{2} \mathrm{PO}_{4}$ was accurately weighed and dissolved in $1000 \mathrm{~mL}$ purified water in the volumetric flask. And then the $\mathrm{KH}_{2} \mathrm{PO}_{4}$ solution was mixed with acetonitrile at the proportion of $70 / 30(\mathrm{~V} / \mathrm{V})$. The $\mathrm{pH}$ of the solution was adjusted to 3.0 using phosphoric acid or $\mathrm{KOH}$. Then the solution was filtered through a $0.45 \mu \mathrm{m}$ membrane filter filtration and degassed before use. The standard samples were prepared by dissolving sodium 
pyruvic acid sample $(0.08 \mathrm{~g}, 0.12 \mathrm{~g}, 0.16 \mathrm{~g}, 0.20 \mathrm{~g}, 0.24 \mathrm{~g}, 0.28 \mathrm{~g}$, and $0.32 \mathrm{~g})$ in the mobile phase.

\section{Analytical methods}

The fermentation liquor was centrifuged at $5000 \mathrm{r} / \mathrm{min}$ for $10 \mathrm{~min}$, and the supernatant was diluted 50 times and analyzed to determine the reducing sugars by the DNS (dinitrosalicylic acid) method ${ }^{26}$. The content of soluble sugar was measured by the common used Phenol-sulfate method. The solution was determined through the 722S spectrophotometer (Shanghai precision instrument co., LTD (Shanghai, China)) at $520 \mathrm{~nm}$ with distilled water as control group. The fermentation broth was distilled first and then ethanol concentration was determined by sulfuric acidpotassium bichromate method ${ }^{27}$ and also by Gas Chromatography (GC17A, SHIMADZU Corporation, Kyoto, Japan). All experiments were carried out for four times. The $\mathrm{pH}$ was measured in a $\mathrm{pH}$ meter (PHS-3B, Shanghai Precision \& Scientific Instrument Co. Ltd, Shanghai, China). The Efficient liquid chromatography spectrometry (LC-10AD vp, SHIMADZU Corporation, Kyoto, Japan) was used for the concentration measurement of important intermediate product in the fermentation culture.

\section{RESULTS AND DISCUSSION}

\section{The key enzyme research}

Alginate was a major polysaccharide in brown algae. Although several bacteria express alginate lyase and can assimilate alginate, existing ethanol fermentation microbes can't degrade alginate as carbon sources ${ }^{28}$. In order to convert alginate to bio-ethanol, alginate fermentation strains should utilize alginate and then generate ethanol in the cell.

In this study, the metabolism procedure of alginate for ethanol production in yeast was studied and the crude enzymes of alginate lyase, pyruvate dehydrogenase and ethanol dehydrogenase were extracted. At the same time, the enzyme activity was measured under different fermentation time.

The alginate lyase activity of the crude enzyme under different fermentation time was measured and the result was shown in Figure 1. The alginate lyase activity reached about $46.2 \mathrm{U} / \mathrm{mL}$ at the fermentation time of 84 hours, compared to 12.79 $\mathrm{U} / \mathrm{mL}$ in the reference ${ }^{23}$, alginate lyase of this strain was much higher, which indicated that this strain might be a promising strain to convert alginate to bioethanol. As shown in the trend curve, the enzyme activity of alginate lyase fermentation $(48 \mathrm{~h}$ ) was not very high, but in $72-84 \mathrm{~h}$ the enzyme activity was significantly increased. At $84 \mathrm{~h}$, the activity reached the highest $46.2 \mathrm{U} / \mathrm{ml}$. But with longer fermentation time, the activity of the strain was decreased also the enzyme activity was decreased too. 


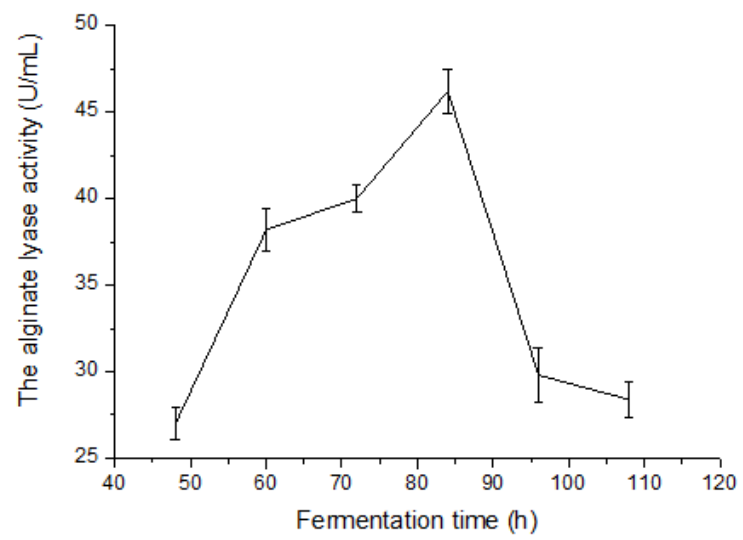

Figure 1- The alginate lyase activity under different fermentation time

The crude pyruvate dehydrogenase was extracted according to the experiment part. The absorbance was measured under $340 \mathrm{~nm}$ according to the reference. The enzyme activity was calculated under different fermentation time. The result was shown in Figure 2. In the pyruvate dehydrogenase activity trend chart, the pyruvate dehydrogenase activity increased gradually at the beginning of fermentation and the highest reached $1.70 \mathrm{U} / \mathrm{mL}$ when the fermentation time was $96 \mathrm{~h}$. But the enzyme activity was reduced when the fermentation time was more than $96 \mathrm{~h}$. Pyruvate dehydrogenase was the most important enzyme to control the pyruvic acid metabolization and the activity became one of the key factors to the whole ethanol metabolism.

During the ethanol fermentation process of the strain, the conversion of pyruvic acid to acetaldehyde was catalyzed by pyruvate dehydrogenase, and then ethanol was generated under the catalyzation effect of ethanol dehydrogenase from acetaldehyde. Enzyme activity of ethanol dehydrogenase reached $126.25 \mathrm{U} / \mathrm{mL}$ under the fermentation time of $72 \mathrm{~h}$, in our experiments the dehydrogenase was got from cells in $40 \mathrm{~mL}$ fermentation culture, and prepared in $20 \mathrm{~mL} \mathrm{~K}$-phosphate buffer $(0.05$ $\mathrm{mol} / \mathrm{L}, \mathrm{pH}$ 8.0). While in the inference $20 \mathrm{~g}$ abandoned beer yeast was suspended in $40 \mathrm{~mL} \mathrm{~K}$-phosphate buffer $(0.08 \mathrm{~mol} / \mathrm{L}, \mathrm{pH} 8.5)$, and according to the reference the highest activity was $1806 \mathrm{U} / \mathrm{mL}^{25}$. Cells in $40 \mathrm{~mL}$ fermentation culture were far less than $20 \mathrm{~g}$, so the activity of dehydrogenase of this strain was actually higher. And as shown in Figure 3, the activity of the ethanol dehydrogenase was small at the beginning of fermentation. But at the fermentation time of 72-84 h, the enzyme activity increased rapidly, so it was the most important time to produce ethanol. With longer fermentation time, the enzyme activity began to decrease.

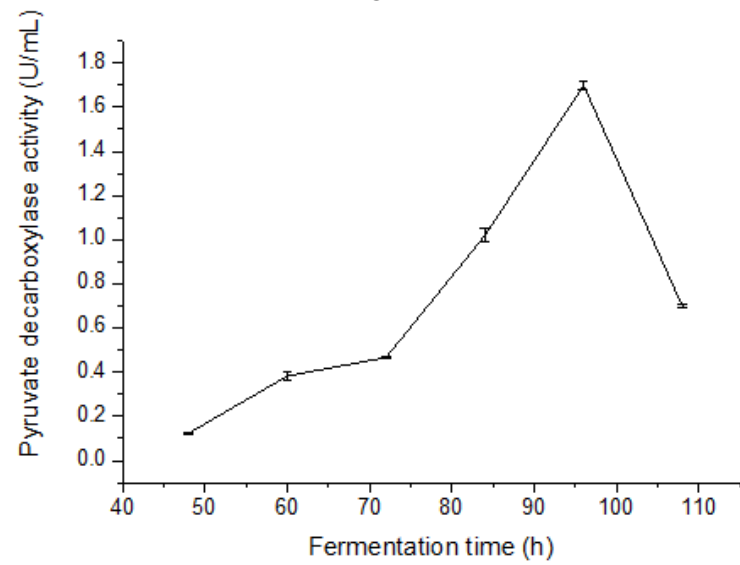

Figure 2- The pyruvate dehydrogenase activity under different fermentation time 
Enzyme and metabolic process tracking

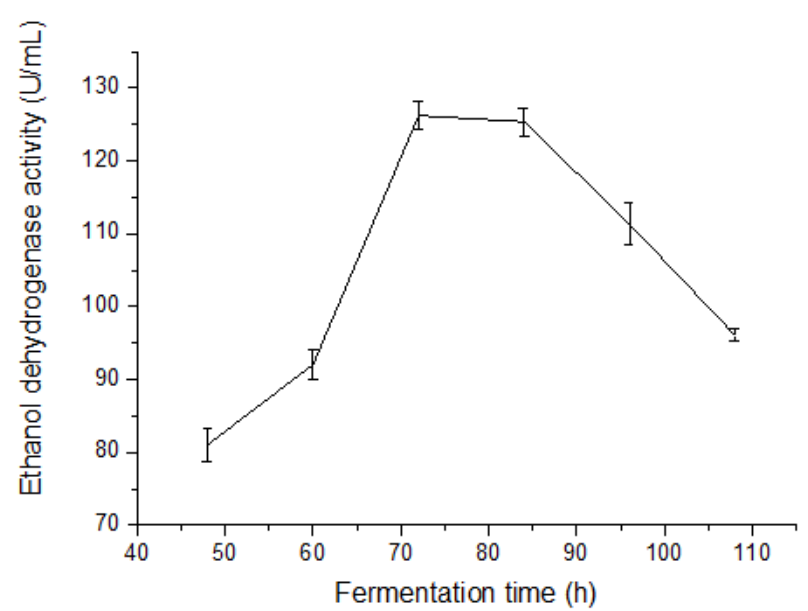

Figure 3- The ethanol dehydrogenase activity under different fermentation time

\section{The track of the substances during the fermentation process}

In this research, the change of the important substances concentration under different fermentation time during the fermentation process was followed, and the changes of substances and ethanol metabolism during the process of metabolism were analyzed.

\section{The track of sugar concentration during the fermentation process}

Firstly, the concentration of the soluble sugar was measured. And the variation of concentration during the fermentation process was analyzed. The concentration was measured by the phenol sulfuric acid method and the standard curve was drawn. The absorbance was measured at $485 \mathrm{~nm}$. The fermentation solution under different fermentation time of $48,60,72,84,96$, and $108 \mathrm{~h}$ was firstly diluted and then centrifuged for $15 \mathrm{~min}$ at $3500 \mathrm{r} / \mathrm{min}$ to remove the sediment. The total soluble sugar content of the supernatant was determined. The results were shown in Figure 4. In this experiment, the difference of the measuring value of the parallel experiment was very small, so the error value was not shown in the diagram, and the accuracy of this experiment was high. Ethanol production experiments were carried out with alginate as the only carbon source. Before fermentation, the fermentation culture was treated by the high temperature sterilization and then cooled down to measure the content of the soluble sugar according to the introduction in the method part. Because alginate did not completely dissolve, the measured sugar value was lower than the actual concentration. During the fermentation process of 48-60 h, the sugar concentration in the fermentation solution dropped quickly, indicating that the strain of this stage was exuberant. In the 72-96 h, water-soluble sugar concentration decreased slowly, but maintained a stable state. The utilization of alginate degradation and microbial fermentation achieved balance during this time. With the fermentation time of $108 \mathrm{~h}$, the soluble sugar concentration increased slightly, and the strain was with low fermentation activity. 


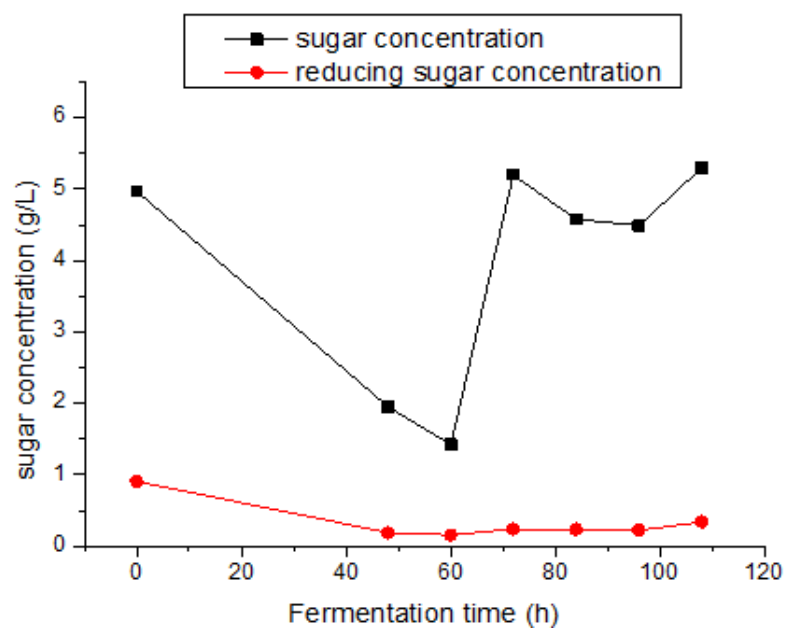

Figure 4- The variation of sugar concentration during the fermentation process

Then, the concentration of reducing sugar during the fermentation was also measured. The concentration was measured by the DNS method and the standard curve was drawn. The absorbance was measured at $520 \mathrm{~nm}$. The fermentation solution under different fermentation time of 48,60, 72, 84, 96, and $108 \mathrm{~h}$ was centrifuged for $15 \mathrm{~min}$ at $3500 \mathrm{r} / \mathrm{min}$ to remove the sediment. The reducing sugar content of the supernatant was determined. The results were also shown in Figure 4. In this experiment, the difference of the measuring value of the parallel experiment was very small, so the error value was not shown in the diagram, and the accuracy of this experiment was high. Alginate was the only carbon source of the fermentation culture. And the fermentation culture was treated by the high temperature sterilization and then cooled down to measure the content of the reducing sugar before fermentation. Because of the high temperature sterilization treatment, the alginate was partly degraded to produce reducing sugars. At the same time, as shown in Figure 4, the variation of the reducing sugar content was the same as the total soluble sugar content. On the basis of previous study of alginate lyase enzyme activity changes, the activity of alginate lyase was increased during the fermentation time of $48-80 \mathrm{~h}$, but at the same time, the microbial fermentation activity at this stage was also very high. The reducing sugar utilization rate of the strains increased. So during the fermentation time of $48-80 \mathrm{~h}$, the reducing sugar concentration maintained at a balanced level which reflected that the alginate degradation and the reducing sugar utilization reached the equilibrium state. And at the end of the fermentation, with slow microbial metabolism, the reducing sugar concentration had a slight increase. During the fermentation, the reducing sugar content in solution was always significantly lower than the total soluble sugar content, and the strain used the reducing sugar for their metabolism.

\section{The track of $\mathrm{pH}$ during the fermentation process}

In this research, the precision $\mathrm{pH}$ meter was used for the determination of $\mathrm{pH}$ in the fermentation broth. The $\mathrm{pH}$ electrode was soaked with saturated potassium chloride solution for $24 \mathrm{~h}$ and preheated for $15 \mathrm{~min}$ before use. The adjacent benzene two formic acid potassium ( $\mathrm{pH} 4.00$ ) and mixed phosphate $(\mathrm{pH}$ 6.86), four boric acid sodium ( $\mathrm{pH}$ 9.18) solutions were used for the calibration of the $\mathrm{pH}$ value. The $\mathrm{pH}$ value of the fermentation process was shown in Figure 5. In the process of fermentation, the fermentation liquid was always in the acidic condition. And the change of the $\mathrm{pH}$ value during the fermentation process was not much, and this was different from the fermentation of Saccharomyces cerevisiae ${ }^{29}$. In the process of 
Enzyme and metabolic process tracking

metabolism, the generation of organic acid in the process of fermentation would affect the $\mathrm{pH}$ of the fermentation liquid. And with the fermentation of 72 hours, the $\mathrm{pH}$ reached the highest acidity. Then, with the extension of fermentation time, the acidity of fermentation liquid was reduced maybe because of the utilization of organic acid.

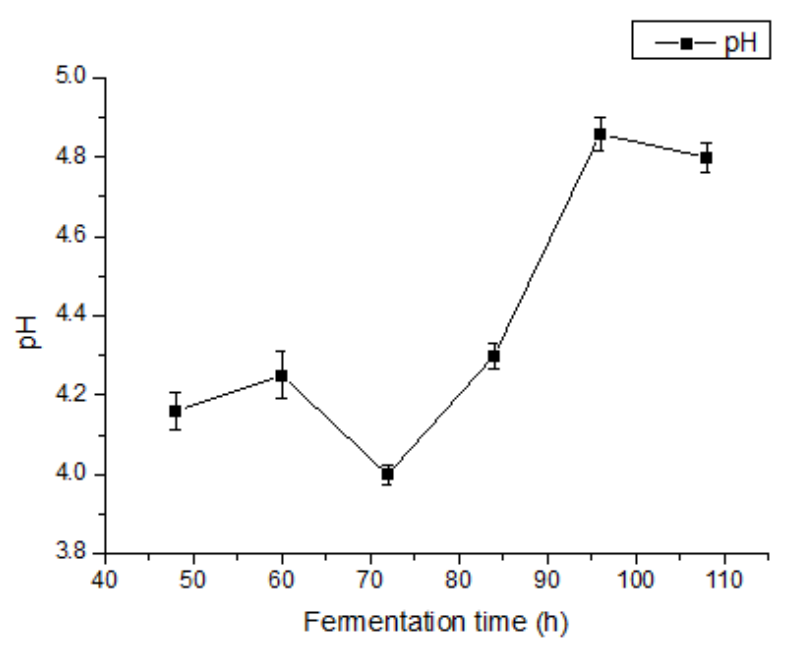

Figure 5- The variation of $\mathrm{pH}$ during the fermentation process

The track of pyruvic acid during the fermentation process

Pyruvic acid is an important intermediate in the alcohol fermentation process for many species of yeast and is a precursor of many metabolic substances ${ }^{30}$. It was related to alcohol concentration ${ }^{31}$.Also during the alcohol fermentation, the concentration of pyruvic acid was found to be strongly influenced by the strain of yeast used to conduct the fermentation, and $\mathrm{pH}$ of the medium, with high $\mathrm{pH}$ correlating with high pyruvic acid content ${ }^{32}$. The pyruvic acid concentration in the fermentation broth was measured according to the experiment part. Firstly the standard samples were prepared and the standard curves of efficient liquid chromatography spectrometry were obtained. The peak area and the concentration of pyruvic acid had the linear relationship. Then the fermentation liquid was pretreated for the chromatographic analysis to determine the pyruvic acid concentrations of different fermentation time. The result was shown in Figure 6. In the whole fermentation process, the concentration of pyruvic acid was firstly increased and then decreased. This experiment result was as the same as the result reported in the reference ${ }^{31}$ and the concentration of pyruvic acid was related to the yeast activity ${ }^{31}$. The pyruvic acid metabolism process was a key link of the whole fermentation process. Pyruvic acid acted as the activator of decarboxylase which promoted the transformation of pyruvic acid to acetaldehyde. And with the effect of ethanol dehydrogenase, ethanol was finally generated. 


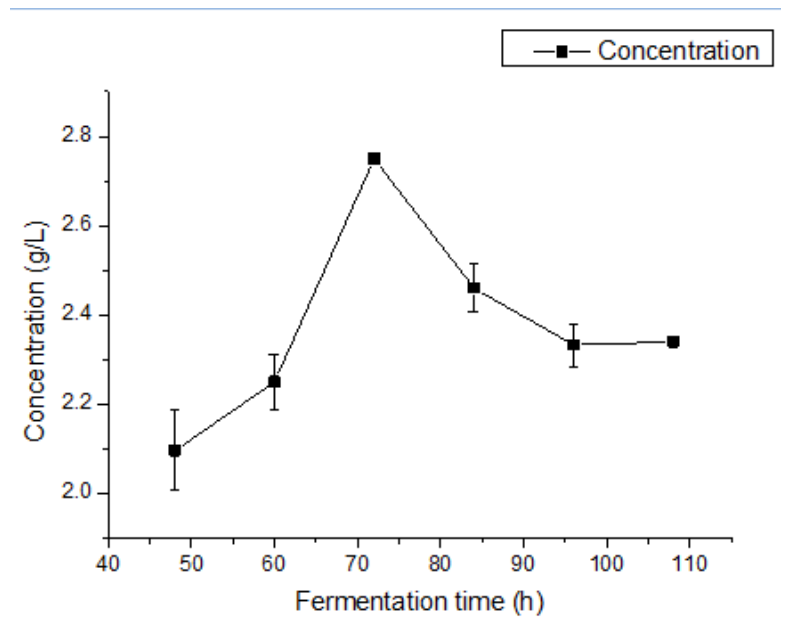

Figure 6- The variation of pyruvic acid concentration during the fermentation process

\section{The track of ethanol during the fermentation process}

In this research, the fermentation conditions were obtained from our previous experiments which introduced the optimum fermentation conditions. Ethanol production experiments were carried out with alginate as the only carbon source. All the fermentation experiments were carried out in $150 \mathrm{~mL}$ flasks with $50 \mathrm{~mL}$ working medium, with an initial $\mathrm{pH}$ of 5.0. All the flasks were cultured in a shaking incubator, with culture conditions as follows: $150 \mathrm{r} / \mathrm{min}, 30{ }^{\circ} \mathrm{C}$ for different fermentation time. In the process of fermentation, ethanol as the end product of the fermentation process, the calculation method of the yield was introduced in the experiment part. In this experiment, the ethanol concentration in the fermentation broth of different fermentation time was measured. The relationship of ethanol yield with fermentation time was as shown in the Figure 7. Ethanol concentration was increased a lot during the fermentation time of 60-96 h. During this period, the growth of ethanol concentration was very obvious and growth rate was very high. Also the enzyme activity of the three key enzymes in the metabolic process was relatively high in the $60-96 \mathrm{~h}$, so this period was the most important during the fermentation. At the same time, compared to the pyruvic acid concentration variation chart, the pyruvic acid concentration was firstly increased and then decreased. In the process of pyruvic acid reducing, the ethanol concentration increased gradually and when the concentration of pyruvic acid reached the lowest value, the ethanol concentration reached the highest. This experiment result was as the same as the result reported in the reference ${ }^{31}$. In addition, with the comparison of enzyme activity data, pyruvate decarboxylase and ethanol dehydrogenase was very important in the process of ethanol fermentation. The enzyme activity influenced the yield of ethanol. From the data analysis, the change trend of pyruvate decarboxylase activity and ethanol concentration were similar and they both reached the highest value at 96 $\mathrm{h}$. But the activity of ethanol dehydrogenase decreased at $96 \mathrm{~h}$. The increase of ethanol concentration may have inhibition effect on ethanol dehydrogenase enzyme activity ${ }^{33}$. 
Enzyme and metabolic process tracking

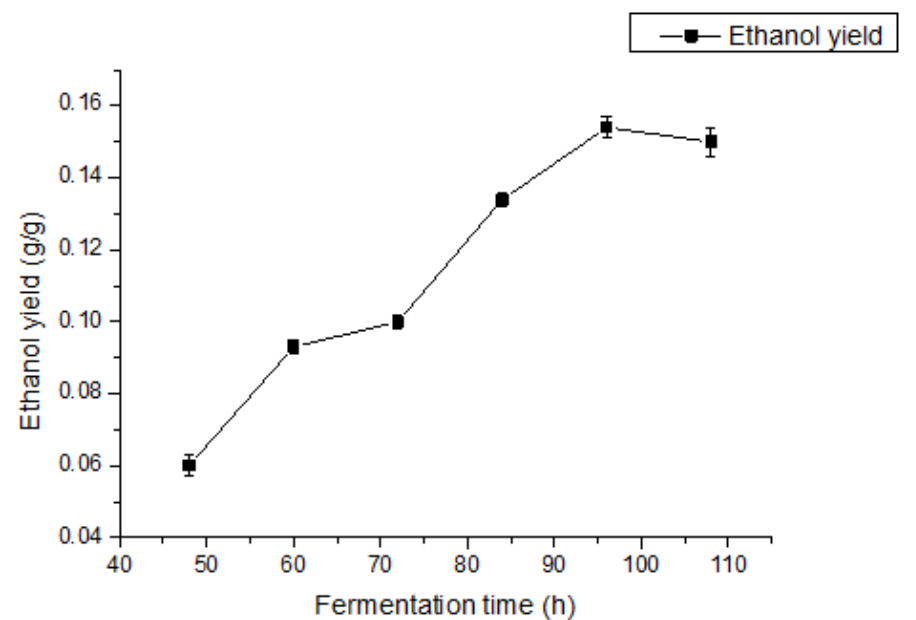

Figure 7- The variation of ethanol yield during the fermentation process

In general, the alginate metabolic process in natural alginate fermentation strain was to generate extracellular alginate lyase to degrade alginate to produce reducing sugar, and then some intermediate metabolites. Finally under the effect of pyruvate dehydrogenase and ethanol dehydrogenase, ethanol was produced.

\section{CONCLUSION}

Brown alga as raw materials for bio ethanol production is becoming the focus of attention in the field of energy. In order to reach the maximum ethanol production, the research on alginate fermentation and alginate metabolism process is very important. The research of alginate metabolic pathway, metabolites and important enzymes will provide the oretical basis for further metabolic and progress control, and also for gene modification and industrial application. Three kinds of key enzyme including alginate lyase, pyruvate dehydrogenase and ethanol dehydrogenase were determined. The alginate lyase activity reached the highest at $84 \mathrm{~h}$, at this time alginate was largely degraded and the sugar for ethanol fermentation was enough. The pyruvate dehydrogenase activity increased gradually at the beginning of fermentation and the highest reached $1.70 \mathrm{U} / \mathrm{mL}$ when the fermentation time was 96 h. Enzyme activity of ethanol dehydrogenase reached highest under the fermentation time of $72 \mathrm{~h}$. The enzyme activity of the three kinds of key enzyme in the metabolic process was relatively high in the 60-96 h, so this period was the most important during the fermentation. At the same time, the concentration change of the important substances including soluble sugar, reducing sugar, $\mathrm{pH}$, pyruvic acid and ethanol under different fermentation time during the fermentation process was followed and analyzed. Total soluble sugar and reducing sugar change tendency during the fermentation was similar. The sugar content was decreased in the beginning, but later increased because of the alginate degradation. Then because of the ethanol fermentation the content was decreased and finally was increased because of the reducing fermentation activity. In the whole fermentation process, the fermentation broth was acidic, and the change of the $\mathrm{pH}$ value during the fermentation was not much. The pyruvic acid content was first increased and then decreased which was similar to the ethanol content variation. The pyruvic acid content highest value reached $2.75 \mathrm{~g} / \mathrm{L}$. 


\section{ACKNOWLEDGMENTS}

This work was supported by the Natural Science Foundation of Hebei Province of China (Youth Fund Project C2014203207), Independent research program of young teachers in Yanshan University 14LGA018, and National Natural Science Foundation of China 21476190.

\section{REFERENCES}

1. Ge L, Wang P, Mou H. Study on saccharification techniques of seaweed wastes for the transformation of ethanol. Renew Energy. 2009;36: 84-89.

2. Choi IS, Kim JH, Wi SG, Kim KH, Bae HJ. Bio-ethanol production from mandarin (Citrus unshiu) peel waste using popping pretreatment. Appl. Energy. 2013;102:204-210.

3. Choi IS, Wi SG, Kim SB, Bae HJ.Conversion of coffee residue waste into bioethanol with using popping pretreatment. Bioresour. Technol. 2012;125: 132-137.

4. Somma D, Lobkowicz H, Deason JP.Growing America's fuel: an analysis of corn and cellulosic ethanol feasibility in the United States. Clean Technol Environ Policy. 2010;12:373-380.

5. Romaní A, Garrote G, Alonso JL, Parajó JC. Bio-ethanol production from hydrothermally pretreated Eucalyptus globulus wood. Bioresour Technol. 2010;101:8706-8712.

6. Mesa L, González E, Cara C, Ruiz E, Castro E, Mussatto SI. An approach to optimization of enzymatic hydrolysis from sugarcane bagasse based on organosolv pretreatment. J Chem Technol Biotechnol. 2010; 85: 1092-1098.

7. Zhang W, Bai A, Chen X, Wei G. Ethanol production from acid hydrolyzates of corn straw with co-immobilized microorganisms. Energy Source: Part A. 2012;34:1206-1212.

8. OECD/FAO, OECD-FAO Agricultural Outlook, OECD Publishing, 2014, http:// dx.doi.org /10.1787/ agr_outlook-2014.

9. Banerjee S, Mudliar S, Sen R, Giri B, Satpute D, Chakrabarti T, Pandey RA. Commercializing lignocellulosic bio-ethanol: technology bottlenecks. Biofuels Bioprod Bioref. 2010;4: 77-93.

10. Zhang W, Wei G. Effects of lignocellulose acid-hydrolysis by-products on ethanol fermentation of xylose. Energy Source: Part A. 2012;34: 1178-1186.

11. Kim HM, Wi SG, Jung S, Song Y, Bae HJ. Efficient approach for bio-ethanol production from red seaweed Gelidium amansii. Bioresour Technol. 2015;175: 128134.

12. Uju, Wijayanta AT, Goto M, Kamiya N. Great potency of seaweed waste biomass from the carrageenan industry for bio-ethanol production by peracetic acideionic liquid pretreatment. Biomass and Bioenergy. 2015;81:63-69.

13. Jung KA, Lim S, Kim Y, Park JM. Potential of macroalgae as feedstock biorefinery. Bioresour Technol. 2013; 135:182-190.

14. Adams JM, Gallagher JA, Donnison IS. Fermentation study on Saccharina latissima for bio-ethanol production considering variable pre-treatments. J Appl Phycol. 2009; 21: 569-574.

15. Wi SG, Kim HJ, Mahadevan SA, Yang DJ, Bae HJ. The potential value of the seaweed Ceylon moss (Gelidium amansii) as an alternative bioenergy resource. Bioresour Technol. 2009; 100:6658-6660.

16. El-Mashad H M. Biomethane and ethanol production potential of Spirulina platensis algae and enzymatically saccharified switchgrass. Biochem Eng J. 2015;93:119-127.

17. Horn SJ, Aasen IM, Østgaard K. Ethanol production from seaweed extract. J. Ind. Microbiol. Biotechnol. 2000; 25:249-254.

18. Lee SM, Lee JH. Ethanol fermentation for main sugar components of brown-algae using various yeasts. J Ind Eng Chem. 2012;18:16-18. 
19. Takeda H, Yoneyama F, Kawai S, Hashimoto W, Murata K. Bio-ethanol production from marine biomass alginate by metabolically engineered bacteria. Energy Environ. Sci, $2011 ; 4$ : 2575-2581.

20. Wargacki AJ, Leonard E, Maung WN, Regitsky DD, Santos CNS, Kim PB, et al. An Engineered Microbial Platform for Direct Biofuel Production from Brown Macroalgae. Science. 2012;335:308-313.

21. Zhang W, Zhang J, Cui H. The Isolation and Performance Studies of an Alginate Degrading and Ethanol Producing Strain. Chem Biochem Eng Q. 2014; 28:391-398.

22. Zhong Z, Li Q, Tang X, Qiu Y. Improvement of the glycerol preserving method. Practical Preventive Medicine. 2005;12:670-671.

23. Chu H, Tang J. Study on culture conditions for alginase production by alginate degrading bacterium Gracillibacillus sp. A7. Marine Sciences. 2008;32:93-96.

24. Gao N, Deng X, Wang P, Li L. Determination of pyruvic acid decarboxylase activity in Saccharomyces cerevisiae. China Brewing. 2011;228:128-130.

25. Mao G, Zhang X, Zhang Y, Di Y. Extraction technology research of alcohol Dehydrogenase from abandoned beer yeast. Journal of Shanxi University of science \& technology. 2007;25:41-44.

26. Miller GL. Use of dinitrosalicylic acid reagent for determination of reducing sugar. Anal. Chem. 1959;31:426-428.

27. Williams M, Reese D. Colorimetric determination of ethyl ethanol. Anal Chem. 1950;22:1556-1561.

28. Wong T, Preston L, Schiller N. Alginate lyase: Review of major sources and enzyme characteristics, structure-function analysis, biological roles, and applications. Annu Rev Microbiol. 2000;54: 289-340.

29. Zhang W, Xiong R, Wei G. Biological flocculation treatment on distillery wastewater and recirculation of wastewater. J Hazard Mater. 2009;172: 1252-1257.

30. Chen X, Wang Y, An J. The Method of determination in pyruvic Acid by HPLC and spectrophotometry. The Food Industry. 2005;36: 290-293.

31. Ito K, Sato J, Kabutomori T, Watanabe S, Taguchi T. Pyruvic acid concentration in moromi -mash as an index of moromi fermentation. J Brew Soc Japan. 2007; 102: 309-313.

32. Rankine BC. Influence of yeast strain and $\mathrm{pH}$ on pyruvic acid content of wines. $\mathbf{J}$ Sci Fd Agric. 1967; 18: 41-44.

33. Nie Y, Dong L, Hou D, Li M, Wang X, Zhao C. Tolerance of key metabolic enzymes on ethanol in the vivo cell of Saccharomyces cerevisiae. Jouranl of Dalian Polytechnic University. 2011;30: 318-321. 